\title{
Diabetes Mellitus among Adult Tuberculosis Patients Attending Tuberculosis Clinics in Eastern Ethiopia
}

\author{
Lucy Tenaye, ${ }^{1}$ Bizatu Mengiste $\left(\mathbb{D},{ }^{1}\right.$ Negga Baraki, ${ }^{1}$ and Ermiyas Mulu ${ }^{2}{ }^{2}$ \\ ${ }^{1}$ College of Health Sciences and Medicine, Haramaya University, Harar, Ethiopia \\ ${ }^{2}$ College of Medicine and Health Sciences, Ambo University, Ambo, Ethiopia \\ Correspondence should be addressed to Ermiyas Mulu; ermiyasmuller@gmail.com
}

Received 9 April 2019; Accepted 17 August 2019; Published 6 November 2019

Academic Editor: Subash Babu

Copyright (c) 2019 Lucy Tenaye et al. This is an open access article distributed under the Creative Commons Attribution License, which permits unrestricted use, distribution, and reproduction in any medium, provided the original work is properly cited.

Background. Developing countries are suffering from the previously existing infectious diseases and alarmingly growing burden of noncommunicable diseases like diabetes mellitus. There is increased speculation that diabetes mellitus might attribute to high infectious diseases burden, such as tuberculosis. The global importance of diabetes mellitus as a tuberculosis-risk factor is still not a well-established fact. Thus, we conducted this study to determine the prevalence of diabetes mellitus and its associated factors among adult tuberculosis patients attending tuberculosis clinics. Methodology. We conducted a cross-sectional survey, from March 10 to April 15, 2017, among 421 tuberculosis patients receiving tuberculosis treatment in health facilities of Dire Dawa City Administration Council, Eastern Ethiopia. Study participants were selected using systematic random technique, and data were collected using a structured questionnaire. Fasting blood sugar and anthropometric measurements were carried out for all participants. A logistic regression analysis was performed to identify factors associated with diabetes mellitus. Result. The prevalence of diabetes mellitus in this study was 13.5\%. Age 26-40 (AOR =6, 95\% CI: $(1.28,27.5)$ ), age $\geq 41(\mathrm{AOR}=9,95 \%$ CI: $(1.9$, $44.4)$ ), and family history of diabetes $(\mathrm{AOR}=3.14,95 \% \mathrm{CI}:(1.23,8.02))$ were found to have a significant association with diabetes mellitus. Conclusion. This study found that the magnitude of diabetes mellitus among tuberculosis patients was higher than the national estimated prevalence of diabetes mellitus in Ethiopia. This study suggests the need for screening each tuberculosis patient for diabetes.

\section{Background}

DM (diabetes mellitus) is defined as a cluster of metabolic disorders, characterized by hyperglycemia high enough to significantly increase the incidence of a specific and unique type of microangiopathy (retinopathy, nephropathy, and neuropathy) [1]. Tuberculosis (TB) is an infectious disease caused by various strains of mycobacterium, especially Mycobacterium tuberculosis and usually attacks the lung [2].

Diabetic patients have the evidence of impaired cellmediated immunity, micronutrient deficiency, pulmonary microangiopathy, and renal insufficiency, all of which predispose to pulmonary tuberculosis (PTB) $[3,4]$. The stress of a severe chronic infection may enhance existing insulin resistance and unmask an underlying $\beta$-cell deficiency leading to hyperglycemia; therefore it is possible that the risk of DM is increased among people with TB, especially in the presence of other predisposing factors [5].

Increases in the burden of noncommunicable diseases and aging populations are changing the importance of different risk factors for tuberculosis and the profile of comorbidities and clinical challenges for people with tuberculosis [6]. Early detection and prompt controlling are important for diabetes mellitus and tuberculosis. Nevertheless, the early diagnosis of diseases is less common in developing countries. The originally existing disease masks the symptoms of the complicating disease. The prognosis and clinical course of each of the two conditions adversely affect the other [7].

The relationship and the merging epidemics of tuberculosis (TB) and diabetes mellitus (DM) in populations with low socioeconomic status have raised concerns among many 
experts [8]. Low-income countries, such as in Ethiopia, are facing double burden of alarming rise in DM prevalence and the highest burden of TB in the world. The possible link between the two diseases will further complicate the problem and seek special concern $[9,10]$.

Several studies have shown that DM increases the risk of $\mathrm{TB}$ and that patients with $\mathrm{TB}$ have higher rates of $\mathrm{DM}$ [11-13]. Diabetes triples the risk of tuberculosis and is also a risk factor for adverse tuberculosis treatment outcomes, including death [14]. These risks are known to become worse in people living with DM, especially if their blood glucose levels are high $[15,16]$.

Given the high prevalence of both DM and TB in Ethiopia, it is likely that many patients have comorbidity $[17,18]$. However, the problem of diabetes in TB patients of Ethiopia is not well documented; although there are pocket studies conducted in a localized area, these pocket studies indicated that problem of diabetes among TB patients is increasing. Therefore, this study aims to assess the diabetes mellitus comorbidity among patients on tuberculosis treatment.

\section{Methods}

2.1. Study Setting. We conducted a cross-sectional study from March 10 to April 15, 2017, in all TB clinics of Dire Dawa city Administrative Council, Eastern Ethiopia. A total of $463 \mathrm{~TB}$ patients were selected, using systematic random sampling technique, from 25 public and private health facilities that were providing TB treatment service in the city.

2.2. Data Collection Procedure. The study used both primary (structured questionnaire, anthropometric measurement, and fasting blood glucose test) and secondary (TB patient smear status, TB treatment category, and type of TB) data collection techniques. Data on sociodemographic and clinical characteristics were collected by interviewing the patients using a structured and pretested questionnaire. The questionnaire was prepared in English and translated into Amharic questions, Afan Oromo, and Somali language (languages spoken by study participants). To check the consistency and clarity of the items in the tool, all versions (Amharic, Afan Oromo, and Somali language) of the questionnaire were pretested on $23 \mathrm{~TB}$ patients attending the TB clinic at Hiwotfana Hospital.

All patients diagnosed as having active TB were screened for DM through their history, previous medical records, and measurement of fasting blood glucose (FBG) concentrations. The glucometer (Prodigy auto code) device was used for the determination of fasting plasma glucose level. Blood sugar status was classified based on the American Diabetes Association cutoff points. Accordingly, patients were classified into three groups: normal $(70-99 \mathrm{~m} / \mathrm{dL})$, prediabetes (100-125 mg/dL), and diabetes ( $\geq 126 \mathrm{mg} / \mathrm{dL})$ [19]. Height and weight of the patients were measured using a digital weight scale and stadiometer. BMI was calculated, and weight status was classified using the WHO cutoff points.
Data collectors and supervisors were trained on the objectives and methodology of the research, data collection and interviewing approach, anthropometric measurement, glucose measurement, and data recording. At least one blood glucose measurement (FPG) was carried out for each patient. In the case of $(F P G) \geq 126 \mathrm{mg} / \mathrm{dL}$, a second determination was performed one week later. Two height and weight measurements were taken from each participant, and procedures were repeated when two measurements did not yield the required precision.

2.3. Data Processing and Analysis. We checked the completeness and consistency of each questionnaire. Then, data were sorted, coded, and entered into a computer using EpiData. After being cleaned by checking for error, impossible or implausible values, and inconsistencies, the data were transferred and analyzed using SPSS version 20 software. The results of the descriptive analysis were summarized using cross tabulation and descriptive statistics. The correlates of DM were assessed using binary logistic regression analysis. Odds ratio with $95 \%$ confidence interval was calculated to measure the strength of association between dependent and independent variables. To control possible confounders, assess factors significantly associated with diabetes and variables associated with $p<0.3$ in the univariable analysis were entered into the multivariable logistic analysis model. Statistical associations were asserted based on $95 \%$ CI and two-sided $5 \%$ level of significance $(\alpha<0.05)$.

\section{Results}

3.1. Diabetes Mellitus. Of the total 463 intended, 430 (92.87\%) patients consented and underwent screening. Thirty-three $(7.8 \%)$ patients refused to participate in the screening. Nine $(1.9 \%)$ patients were excluded from the analysis, as they did not have a confirmatory result for DM. As a result, 421 (90.92\%) participants were included in the final analysis.

Our FPG assessment showed that about $13.5 \%$ of $\mathrm{TB}$ patients had DM comorbidity (FPG $\geq 126 \mathrm{mg} / \mathrm{dL}$ ) and about one-third $(29.7 \%)$ of TB patients had impaired fasting plasma glucose value (FPG 100-125 mg/dL) (Figure 1). About half of diabetic comorbid (52.7\%) was known patients while the remaining were newly diagnosed diabetic patients. Nearly one in twelve diabetic individuals reported that they had a family history of diabetes mellitus.

3.2. Sociodemographic and Clinical Characteristics. The mean age of the participants was $34.08( \pm 15.126)$ years, and males were the majority $(55.8 \%)$. Most of the study participants (90.9\%) were urban dwellers. About three-fourths of the patients had attended at least primary education (Table 1).

Three-hundred thirty-eight $(80.3 \%)$ of the study participants were PTB patients, and of these, one-hundred eighty-eight $(44.6 \%)$ were smear-positive. Majority of (14.2\%) of TBDM patients were PTB Patients. The overall 


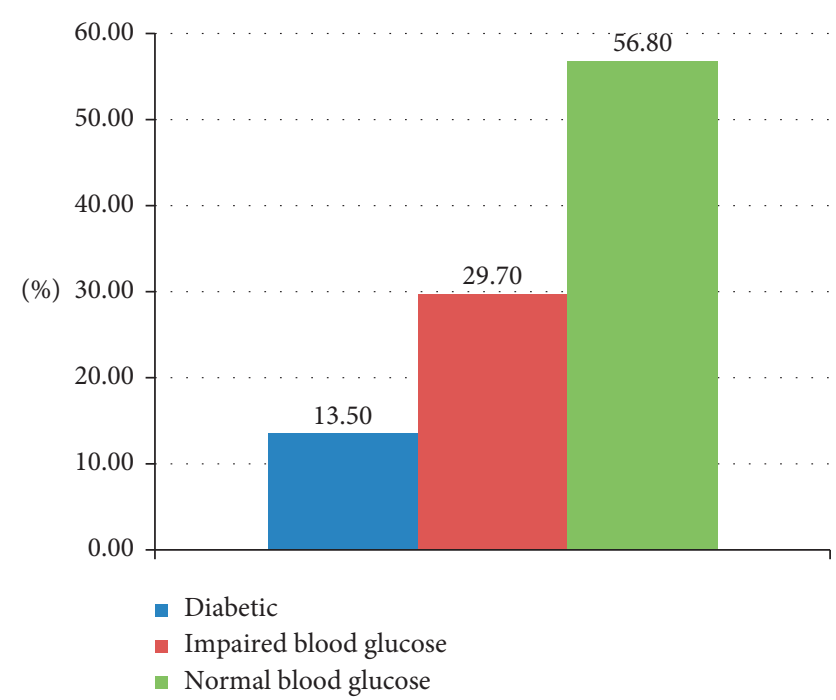

Figure 1: Fasting plasma glucose level of TB patients.

prevalence of chronic energy deficiency and overweight of TB patients was 40.8 and $6.4 \%$, respectively. It seems that the risk of diabetes comorbidity increases by twofold for normal weight and fourfold for overweight TB patients compared with their underweight counterparts (Table 2).

\subsection{Factors Associated with Diabetes Mellitus among TB} Patients. We conducted a binary logistic regression analysis to identify the factors correlated with DM among patients on TB treatment. In the univariable analysis; age, education, occupation, and family history of diabetes had a significant statistical association $(p<0.05)$ with DM. A multivariable direct logistic regression analysis was performed to detect factors significantly associated with DM. Independent variables that showed significant association at $p<0.3$ were entered into the final model (multivariable logistic analysis). The model contained nine independent variables (sex, age, marital status, occupation, education, family history, BMI, TB treatment category, and type of TB).

As indicated in Table 3, only age and family history of diabetes made a unique statistically significant contribution to the model. The age of the patients was a strong predictor of diabetes mellitus, recording odds ratio of 9 ( $\geq 41$ years) and 6 (26-40 years old). These indicate that TB patients older than 41 years were 9 times $(\mathrm{AOR}=9.74,95 \% \mathrm{CI}:(2.69,20.6)$ ) and between 26 and 40 years were 6 times ( $\mathrm{AOR}=6,95 \% \mathrm{CI}$ : $1.28,27.5)$ more likely to be diabetic compared to younger age (between 18 and 25 years) TB patients. TB patients who have a family history of diabetes is 3 times ( $\mathrm{AOR}=3.14,95 \%$ CI: $(1.23,8.02))$ more diabetic compared with those who had no family history of diabetes.

\section{Discussion}

The prevalence of DM among patients with TB in Eastern Ethiopia was higher than the national estimated prevalence of DM $[17,20]$. Similar studies conducted in India and Mexico reported a higher prevalence of diabetes mellitus
TABLE 1: Sociodemographic characteristics of TB patients.

\begin{tabular}{|c|c|c|c|}
\hline Variables & Nondiabetic & Diabetic & Total \\
\hline \multicolumn{4}{|l|}{ Sex } \\
\hline Male & $207(88.1 \%)$ & $28(12 \%)$ & $\begin{array}{c}235 \\
(55.8 \%)\end{array}$ \\
\hline Female & $157(84.4 \%)$ & $29(15.6 \%)$ & $\begin{array}{c}186 \\
(44.2 \%)\end{array}$ \\
\hline \multicolumn{4}{|l|}{ Marital status } \\
\hline Single & $171(95 \%)$ & $9(5 \%)$ & $\begin{array}{c}180 \\
(42.7 \%)\end{array}$ \\
\hline Married & $175(80.6 \%)$ & $\begin{array}{c}42 \\
(19.35 \%)\end{array}$ & $217(51.5 \%)$ \\
\hline Divorced & $9(69.2 \%)$ & $4(30.78 \%)$ & $13(3.08 \%)$ \\
\hline Widowed & $9(81.8 \%)$ & $2(18.2 \%)$ & $11(2.6 \%)$ \\
\hline \multicolumn{4}{|l|}{ Age in year } \\
\hline $18-25$ & $137(96.5 \%)$ & $5(3.5 \%)$ & $\begin{array}{c}142 \\
(33.7 \%)\end{array}$ \\
\hline $26-40$ & $134(85.4 \%)$ & $23(14.6 \%)$ & $\begin{array}{c}157 \\
(37.3 \%)\end{array}$ \\
\hline$\geq 41$ & $93(76.2 \%)$ & $29(23.8 \%)$ & $122(29 \%)$ \\
\hline \multicolumn{4}{|l|}{ Residence } \\
\hline Urban & $331(86.4 \%)$ & $52(13.6 \%)$ & $\begin{array}{c}383 \\
(90.9 \%)\end{array}$ \\
\hline Rural & $33(86.8 \%)$ & $5(13.2)$ & $38(9.02 \%)$ \\
\hline \multicolumn{4}{|l|}{ Educational status } \\
\hline No formal education & $88(78.6 \%)$ & $24(21.4 \%)$ & $\begin{array}{c}112 \\
(26.6 \%)\end{array}$ \\
\hline Elementary school & $102(89.5 \%)$ & $12(10.5 \%)$ & $114(27.1 \%)$ \\
\hline Secondary school & $139(89.7 \%)$ & $16(10.3 \%)$ & $\begin{array}{c}155 \\
(36.8 \%)\end{array}$ \\
\hline Higher education & $35(87.5 \%)$ & $5(12.5 \%)$ & $40(9.5 \%)$ \\
\hline \multicolumn{4}{|l|}{ Occupational status } \\
\hline House wife & $49(80.3 \%)$ & $12(19.7 \%)$ & $61(14.5 \%)$ \\
\hline Unemployed & $56(82.3 \%)$ & $12(17.6 \%)$ & $68(16.1 \%)$ \\
\hline Daily labour & $47(79.6 \%)$ & $12(20.3 \%)$ & $59(14 \%)$ \\
\hline Merchant & $87(91.6 \%)$ & $8(8.4 \%)$ & $95(22.6 \%)$ \\
\hline $\begin{array}{l}\text { Government } \\
\text { employee }\end{array}$ & $64(86.5 \%)$ & $10(13.5 \%)$ & $74(17.6 \%)$ \\
\hline Others & $61(95.3 \%)$ & $3(4.7 \%)$ & $64(15.2 \%)$ \\
\hline \multicolumn{4}{|l|}{ Income } \\
\hline$<1000$ & $83(85.6 \%)$ & $14(14.4 \%)$ & $97(23 \%)$ \\
\hline $1000-2000$ & $150(85.2 \%)$ & $26(14.7 \%)$ & $176(41.8 \%)$ \\
\hline $2001-3000$ & $66(85.7 \%)$ & $11(14.3 \%)$ & $77(18.3 \%)$ \\
\hline$>3000$ & $65(91.5 \%)$ & $6(8.45 \%)$ & $71(16.8 \%)$ \\
\hline
\end{tabular}

comorbidity among TB than our finding $[11,21]$. On the other hand, studies carried out in Nigeria (1.9\%), China (3.2\%), Ethiopia (8.5\%), Tanzania (7.81\%), and Uganda (8.5\%) revealed a lower prevalence of DM among TB patients than our finding [5, 22-25]. The wide range of prevalence of DM in different studies might be due to the difference in sociodemographic characteristics of source populations in the localities studied and screening methods used in DM diagnosis.

Type II diabetes mellitus and other lifestyle-related chronic diseases are more prevalent in old age. In this study, most of the DM-positive individuals were greater than or equal to 41 years of age. When age is increased, the prevalence of DM also increases, which was consistent with the studies done in Ethiopia and Kerala, India [11, 13, 23, 26, 27]. 
TABLE 2: Clinical characteristics and lifestyle of TB patients by diabetes mellitus.

\begin{tabular}{|c|c|c|c|}
\hline Variables & TB patients & TB patients with DM & Total \\
\hline \multicolumn{4}{|l|}{$B M I$} \\
\hline$<18.5$ & $157(91.3 \%)$ & $15(8.7 \%)$ & $172(40.8 \%)$ \\
\hline $18.5-24.9$ & $188(85.1 \%)$ & $33(15 \%)$ & $221(52.5 \%)$ \\
\hline $25-29.9$ & $16(76.2 \%)$ & $5(23.8 \%)$ & $21(5 \%)$ \\
\hline$\geq 30$ & $2(33.3 \%)$ & $4(66.7 \%)$ & $6(1.4 \%)$ \\
\hline \multicolumn{4}{|l|}{ Family history of DM } \\
\hline Yes & $23(69.7 \%)$ & $10(30.3 \%)$ & $33(7.84 \%)$ \\
\hline No & $256(88 \%)$ & $35(12 \%)$ & $291(69.1 \%)$ \\
\hline Not known & $85(87.6 \%)$ & $12(12.4 \%)$ & $97(23 \%)$ \\
\hline \multicolumn{4}{|l|}{ Chat chewing } \\
\hline Yes & $145(87.4)$ & $21(12.6 \%)$ & $166(39.4 \%)$ \\
\hline No & $219(85.8)$ & $36(14.1 \%)$ & $255(60.6 \%)$ \\
\hline \multicolumn{4}{|l|}{ Cigarette smoking } \\
\hline Never smoke & $293(87.2 \%)$ & $43(12.8 \%)$ & $336(79.8 \%)$ \\
\hline Primary cigars smoke & $26(83.8 \%)$ & $5(16.1 \%)$ & $31(7.4 \%)$ \\
\hline Ex cigars smoker & $40(83.3 \%)$ & $8(16.7 \%)$ & $48(11.4 \%)$ \\
\hline Secondary cigar smoker & $5(83.3 \%)$ & $1(16.7 \%)$ & $6(1.4 \%)$ \\
\hline \multicolumn{4}{|l|}{ TB treatment category } \\
\hline Category 1 & $308(87.7 \%)$ & $43(12.25 \%)$ & $351(83.4 \%)$ \\
\hline Category 2 & $56(80 \%)$ & $14(20 \%)$ & $70(16.6 \%)$ \\
\hline \multicolumn{4}{|l|}{ Type of TB } \\
\hline Smear + ve PTB & $157(91.3 \%)$ & $31(16.5 \%)$ & $188(44.6 \%)$ \\
\hline Smear -ve PTB & $133(88.7 \%)$ & $17(11.3 \%)$ & $150(35.6 \%)$ \\
\hline ЕРТВ & $74(89.2 \%)$ & $9(10.8 \%)$ & $83(19.7 \%)$ \\
\hline
\end{tabular}

$\mathrm{DM}=$ diabetes mellitus; $\mathrm{EPTB}=$ extrapulmonary tuberculosis; $\mathrm{PTB}=$ pulmonary tuberculosis; $\mathrm{TB}=$ tuberculosis.

TABLE 3: Factors associated with diabetes mellitus among patients tuberculosis on treatment, Eastern Ethiopia.

\begin{tabular}{|c|c|c|c|c|c|}
\hline \multirow{2}{*}{ Variable } & \multirow{2}{*}{ Category } & \multicolumn{2}{|c|}{ TB comorbid with DM } & \multirow{2}{*}{$\operatorname{COR}(95 \% \mathrm{CI})$} & \multirow{2}{*}{$\operatorname{AOR}(95 \% \mathrm{CI})$} \\
\hline & & Yes & No & & \\
\hline \multirow{2}{*}{ Sex } & Male & $28(12 \%)$ & $207(88.1 \%)$ & $0.73(0.42,1.3)$ & $0.515(0.25-1.16)$ \\
\hline & Female & $29(15.6)$ & $157(84.4 \%)$ & & \\
\hline \multirow{3}{*}{ Age } & $18-25$ & $5(3.5 \%)$ & $137(96.5 \%)$ & & \\
\hline & $26-40$ & $23(14.6 \%)$ & $134(85.4 \%)$ & $4.703(1.74,12.7)^{*}$ & $6(1.282-27.5)^{*}$ \\
\hline & $\geq 41$ & $29(23.8 \%)$ & $93(76.2 \%)$ & $8.544(3.2,22.8)^{*}$ & $9(1.9-44.4)^{*}$ \\
\hline \multirow{2}{*}{ Marital status } & Single & $15(7.4 \%)$ & $189(92.6 \%)$ & & \\
\hline & Married & $42(19.4 \%)$ & $175(80.6 \%)$ & $0.331(0.18,0.617)$ & $1.5(0.692-3.41)$ \\
\hline \multirow{6}{*}{ Occupational status } & House wife & $12(19.7 \%)$ & $49(80.3 \%)$ & $1.57(0.63,3.925)$ & $0.7(0.184-2.74)$ \\
\hline & Unemployed & $12(17.6 \%)$ & $56(82.3 \%)$ & $1.4(0.551,3.42)$ & $1.3(0.380-4.4)$ \\
\hline & Daily labour & $12(20.3 \%)$ & $47(79.6 \%)$ & $1.63(0.651,4.1)$ & $1.62(0.5-5.31)$ \\
\hline & Merchant & $8(8.4 \%)$ & $87(91.6 \%)$ & $0.59(0.22-1.575)$ & $0.52(0.152-1.75)$ \\
\hline & Government & $10(13.5 \%)$ & $64(86.5 \%)$ & & \\
\hline & Others & $3(4.7 \%)$ & $61(95 \%)$ & $0.315(0.08-1.2)$ & $2.3(0.32-17.4)$ \\
\hline \multirow{3}{*}{ Educational status } & Have no formal education & $24(21.4 \%)$ & $88(78.6 \%)$ & $1.91(0.675,5.402)$ & $1.7(0.366-7.450)$ \\
\hline & Primary/secondary & $12(10.5 \%)$ & $102(89.5 \%)$ & $0.8(0.29-2.245)$ & $1.03(0.28-3.8)$ \\
\hline & Higher education & $16(10.3 \%)$ & $139(89.7 \%)$ & & \\
\hline \multirow{2}{*}{ Family history of diabetes } & Yes & $10(30.3 \%)$ & $23(69.7 \%)$ & $3.154(1.4,7.04)^{*}$ & $3.14(1.232-8.02)^{*}$ \\
\hline & No & $47(12 \%)$ & $341(88 \%)$ & & \\
\hline \multirow{3}{*}{ BMI } & $<18.5$ & $15(8.7 \%)$ & $157(91.3 \%)$ & & \\
\hline & $18.5-24.9$ & $33(15 \%)$ & $188(85.1 \%)$ & $1.87(0.98,3.57)$ & $1.95(0.97-3.9)$ \\
\hline & $\geq 25$ & $9(33.3 \%)$ & $18(66.7 \%)$ & $4.74(1.836,12.24)^{*}$ & $2.72(0.911-8.105)$ \\
\hline \multirow{2}{*}{ TB treatment category } & Category 1 & $43(12.25 \%)$ & $308(87.7 \%)$ & & \\
\hline & Category 2 & $14(20 \%)$ & $56(80 \%)$ & $1.791(0.92,3.5)$ & $0.56(0.261-1.2)$ \\
\hline \multirow{3}{*}{ Type of TB } & Smear +ve PTB & $31(16.5 \%)$ & $157(91.3 \%)$ & $1.6(0.735,3.6)$ & $2.31(0.87-6.1)$ \\
\hline & Smear -ve PTB & $17(11.3 \%)$ & $133(88.7 \%)$ & $1.05(0.45,2.5)$ & $1.6(0.575-4.4)$ \\
\hline & ЕРТВ & $9(10.8 \%)$ & $74(89.2 \%)$ & & \\
\hline
\end{tabular}

*Significant at $p<0.05 ; \mathrm{DM}=$ diabetes mellitus; $\mathrm{EPTB}=$ extrapulmonary tuberculosis; $\mathrm{PTB}=$ pulmonary tuberculosis; $\mathrm{TB}=$ tuberculosis. 
Increasing age is linked to immune suppression and is one of the risk factors for both TB and DM [28].

Diabetes is a disease which has strong clustering in families, and family history of DM is a risk factor for DM [29-31]. The result of our study demonstrated this fact; the prevalence of DM was higher among patients who have a family history of DM. This finding is supported by the shreds of evidence from other studies conducted in Ethiopia and other developing countries [13, 25, 32]. This fact might suggest the gap and necessity of revising the existing screen and management approach, individual, of diabetes mellitus.

The proportion of new DM patients $27(6.4 \%)$ identified in our study was higher than the figures documented by similar studies from China (3\%) and Ethiopia [22, 33]. A study from India revealed a higher proportion of new DM (9.3\%) among TB patients [13]. Development of Type II DM is a gradual process. Symptomatic type II DM is a result of unnoticeable body metabolism alterations in years. Prediabetes and diabetes screening is important to reduce the risk of developing diabetes and manage the disease in early stages. The high proportion of new DM patients among our study participants indicates low diabetes screening coverage in TB clinics [34]. Therefore, the finding of this research calls for the implementation of active case finding of DM in patients diagnosed for $\mathrm{TB}$ and also for the integrating of $\mathrm{TB}$ and DM care programs.

In this study, the overall proportion of prediabetes among TB patients was $29.7 \%$, which is consistent with a similar study performed in Gonder, Ethiopia [35]. Prediabetes is a condition characterized by abnormally high blood glucose but lower than the diabetic range. Prediabetes individuals have a higher risk of developing DM; each year about $5 \%$ to $10 \%$ of prediabetes individuals develop DM [36]. Provided low diabetes screening coverage and health promotion activity in Ethiopia, the current number of DM patients may surge significantly in the near future [35]. The observed DM and prevalence of prediabetes in the studied group warrants integrated health services approach to address the burden of the two diseases.

The authors acknowledge that exclusion of uncertain first blood glucose results will be a possible limitation of this study. A significant number of TB patients, whose first DM test result was not conclusive to determine the DM status, were excluded from the analysis. As a result, we may have underestimated the prevalence of DM among TB patients.

\section{Conclusion}

The magnitude of DM among TB patients in the study settings, Dire Dawa, was higher than the national estimated prevalence of DM in Ethiopia. Age and family history of diabetes were found to have significant association with diabetes mellitus. About half of the DM patients in this study were diagnosed for the first time during this study. Therefore, the concerned body should give attention to implementing diabetes screening and comprehensive chronic care at $\mathrm{TB}$ clinics as it might have a beneficial impact on $\mathrm{TB}$ control and management of diabetes mellitus. Advance studies are needed for further understanding of the relationships and management approaches of TB-DM comorbidity.
Abbreviations
ADA: American Diabetic Association
BMI: Body mass index
CI: $\quad$ Confidence interval
DM: Diabetes mellitus
EPTB: Extrapulmonary tuberculosis
FBG: Fasting blood glucose
FPG: Fasting plasma glucose
mg/dL: milligram/deciliter
HIV: Human immunodeficiency virus
IDF: International Diabetes Federation
IFG: Impaired fasting glucose
IGT: Impaired glucose tolerance
MTB: Mycobacterium tuberculosis
NCDs: Noncommunicable diseases
OGTT: Oral glucose tolerance test
PTB: Pulmonary tuberculosis
RBS: Random blood sugar
TB: Tuberculosis
WHO: World Health Organization.

\section{Data Availability}

The full data used to support the findings of this study are available at the hands of the first author upon request.

\section{Ethical Approval}

The Institutional Health Research Ethics Review Committee (IHRERC) of Haramaya University had approved the study.

\section{Consent}

An informed written and signed consent was obtained from all participants for their participation after the nature of the study was fully explained to them in their local languages. A thumbprint or signature was used on the consent form. The entire study participants were informed that data will be kept private and confidential and used only for research purpose. The participants also assured that they have the right to refuse or withdraw if they are not comfortable at any time. If the participant is diagnostic with prediabetic, he/she may be referred to the hospital for chronic care proper treatment and follow-up of this disease. After the compilation of data collection, all of the participants were educated about risk factors, consequences, and compilations of diabetes mellitus and tuberculosis.

\section{Disclosure}

This manuscript is based on the MPH thesis work of Lucy Tenaye. The funder did not participate in the research design, data collection, and manuscript preparation process. 


\section{Conflicts of Interest}

The authors declare that they have no conflicts of interest.

\section{Authors' Contributions}

LT, BM, and NB were involved in the conception of the study and performed the study. EM, BM, and LT took part in the interpretation of result and manuscript development. All the authors read and approved the final manuscript.

\section{Acknowledgments}

We would like to acknowledge Dire Dawa City Administration Health Office and health facility staffs for providing all the necessary background information and cooperation during data collection time. Our special thanks also extend to data collectors, supervisors, and study participants for their genuine participation and contribution. The financial support of this research was obtained from the Haramaya University.

\section{References}

[1] WHO and NCD, Definition, Diagnosis, and Classification of Diabetes Mellitus and its Complications: Part 1: Diagnosis and Classification of Diabetes Mellitus Report of a WHO Consultation, Vol. 2, WHO, Geneva, Switzerland, 1999.

[2] WHO (World Health Organization), World Health Organization, Global Tuberculosis Report 2015, WHO/HTM/TB, Geneva, Switzerland, 2016.

[3] M. Reid, N. McFadden, and B. Tsima, "Clinical challenges in the co-management of diabetes mellitus and tuberculosis in Southern Africa," Journal of Endocrinology, Metabolism and Diabetes of South Africa, vol. 18, no. 3, pp. 135-140, 2013.

[4] G. Elorriaga, G. Pineda, and R. Del, "Type 2 diabetes mellitus as a risk factor for tuberculosis," Mycobacterial Diseases, vol. 4, no. 2, 2014.

[5] V. J. Mallikarjun, V. K. Mahishale, and M. B. Hiremath, "Bidirectional screening of tuberculosis patients for diabetes mellitus and diabetes patients for tuberculosis," Diabetes \& Metabolism Journal, vol. 37, no. 4, pp. 291-295, 2013.

[6] WHO (World Health Organization), Global Tuberculosis Control, WHO, Geneva, Switzerland, 2009.

[7] S. Malin and K. McAdam, "Escalating threat from tuberculosis: the third epidemic," Thorax, vol. 50, no. Supp 1, pp. S37-S42, 1995.

[8] K. Park, Park Textbook of Preventive and Social Medicine India, Banarsidas Bhanot, Bhopal, India, 2011.

[9] M. Cheng, "Asia-Pacific faces diabetes challenge," The Lancet, vol. 375, no. 9733, pp. 2207-2210, 2013.

[10] L. Chen, D. J. Magliano, and P. Z. Zimmet, "The worldwide epidemiology of type 2 diabetes mellitus-present and future perspectives," Nature Reviews Endocrinology, vol. 8, no. 4, pp. 228-236, 2012.

[11] S. Balakrishnan, S. Vijayan, S. Nair, J. Subramoniapillai, S. Mrithyunjayan, and N. Wilson, "High diabetes prevalence among tuberculosis patients in Kerala, India," PLoS One, vol. 7, no. 10, Article ID e46502, 2012.

[12] B. I. Restrepo, A. J. Camerlin, M. H. Rahbar et al., "Crosssectional assessment reveals high diabetes prevalence among newly-diagnosed tuberculosis cases," Bulletin of the World Health Organization, vol. 89, no. 5, pp. 352-359, 2011.
[13] V. Viswanathan, S. Kumpatla, V. Aravindalochanan et al., "Prevalence of diabetes and pre-diabetes and associated risk factors among tuberculosis patients in India," PLoS One, vol. 7, no. 7, Article ID e41367, 2012.

[14] B. I. Restrepo and L. S. Schlesinger, "Impact of diabetes on the natural history of tuberculosis," Diabetes Research and Clinical Practice, vol. 106, no. 2, pp. 191-199, 2014.

[15] C. R. Stevenson, J. A. Critchley, N. G. Forouhi et al., "Diabetes and the risk of tuberculosis: a neglected threat to public health?," Chronic Illness, vol. 3, no. 3, pp. 228-245, 2007.

[16] S. Ottmani, M. B. Murray, C. Y. Jeon, M. A. Baker, A. Kapur, and K. Lonnroth, "Consultation meeting on tuberculosis and diabetes mellitus," International Journal of Tuberculosis and Lung Disease, vol. 14, no. 12, pp. 1513-1517, 2010.

[17] T. Nigatu, "Epidemiology, complications and management of diabetes in Ethiopia: a systematic review," Journal of Diabetes, vol. 4, no. 2, pp. 174-180, 2012.

[18] WHO (World Health Organization), Global Tuberculosis Report 2015, WHO/HTM/TB, Geneva, Switzerland, 2016.

[19] American Diabetes Association, "Classification and diagnosis of diabetes," Diabetes Care, vol. 39, no. Supp 1, pp. S13-S22, 2016.

[20] International Diabetes Federation, IDF Diabetes Atlas, International Diabetes Federation, Brussels, Belgium, Seventh Edition, 2015, http://www.diabetesatlas.org.

[21] P. Alfredo, G. Lourdes, S. Cecilia et al., "Tuberculosis and diabetes in Southern Mexico," Diabetes Care, vol. 27, no. 7, pp. 1584-1590, 2004.

[22] Q. Wang, X. Han, A. Ma et al., "Screening and intervention of diabetes mellitus in patients with pulmonary tuberculosis in poverty zones in China: rationale and study design," Diabetes Research and Clinical Practice, vol. 96, no. 3, pp. 385-391, 2011.

[23] M. H. Workneh, G. A. Bjune, and S. A. Yimer, "Prevalence and associated factors of diabetes mellitus among tuberculosis patients in South-Eastern Amhara region, Ethiopia: a crosssectional study," PLoS One, vol. 11, no. 1, Article ID e0147621, 2016.

[24] D. Faurholt-Jepsen, N. Range, G. PrayGod et al., "Diabetes is a risk factor for pulmonary tuberculosis: a case-control study from Mwanza, Tanzania," PLoS One, vol. 6, no. 8, Article ID e24215, 2011.

[25] K. Davis, S. Richard, M. I. Edrisa, and W. William, "Overt diabetes mellitus among newly diagnosed Ugandan tuberculosis patients," BMC Infectious Diseases, vol. 13, no. 122, pp. 1471-2334, 2013.

[26] D. Emeshaw, A. Ibrahim, and M. Daniel, "Prevalence of diabetes mellitus among active pulmonary tuberculosis patients at st. Peter specialized hospital, Addis Ababa, Ethiopia," World Journal of Medical Sciences, vol. 11, no. 3, pp. 389-396, 2014.

[27] K. Vasudevan, S. Govindarajan, P. Chinnakali, K. Panigrahi, and S. Raghuraman, "Prevalence of diabetes mellitus among tuberculosis patients in urban Puducherry," North American Journal of Medical Sciences, vol. 6, no. 1, pp. 30-34, 2014.

[28] A. Hiwot, G. Aschalew, A. Belay, and G. Baye, "Smear positive pulmonary tuberculosis among diabetic patients at the Dessie referral hospital, Northeast Ethiopia," Infectious Diseases of Poverty, vol. 2, no. 1, 2013.

[29] R. Dhananjayan, T. Malati, G. Brindha, and V. K. Kutala, "Association of family history of type 2 diabetes mellitus with markers of endothelial dysfunction in South Indian population," Indian Journal of Biochemistry and Biophysics, vol. 50, no. 2, pp. 93-98, 2013. 
[30] A. Ramachandran, "Epidemiology of type 2 diabetes in India," Journal of the Indian Medical Association, vol. 100, pp. 425427, 2002.

[31] B. E. K. Klein, R. Klein, S. E. Moss, and K. J. Cruickshanks, "Parental history of diabetes in a population-based study," Diabetes Care, vol. 19, no. 8, pp. 827-830, 1996.

[32] Q. Wang, A. Mai, X. Han, S. Zhao, J. Cai, and Y. Ma, "Prevalence of type 2 diabetes among newly detected pulmonary tuberculosis patients in China: a community based cohort study," PLoS One, vol. 8, no. 12, Article ID e82660, 2013.

[33] L. Liang, L. Yan, M. Fengling, T. Shouyong, L. Bing, and G. Chaojun, "Screening of patients with tuberculosis for diabetes mellitus in China," Tropical Medicine and International Health, vol. 17, no. 10, pp. 1294-1301, 2013.

[34] American Diabetes Association, "Classification and diagnosis of diabetes: standards of medical care in diabetes-2019," Diabetes Care Jan, vol. 42, no. Supplement 1, pp. S13-S28, 2019.

[35] G. Assefa, M. Solomon, A. Shiatye, and Y. Hanan, "High magnitude of diabetes mellitus among active pulmonary tuberculosis patients in Ethiopia," British Journal of Medicine \& Medical Research, vol. 4, no. 3, pp. 862-872, 2013.

[36] A. G. Tabák, C. Herder, W. Rathmann, E. J. Brunner, and M. Kivimäki, "Prediabetes: a high-risk state for diabetes development," The Lancet, vol. 379, no. 9833, pp. 2279-2290, 2012. 


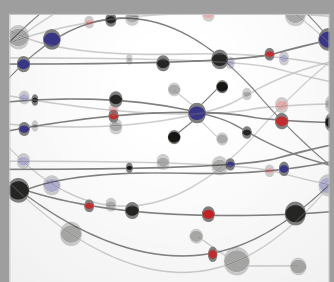

The Scientific World Journal
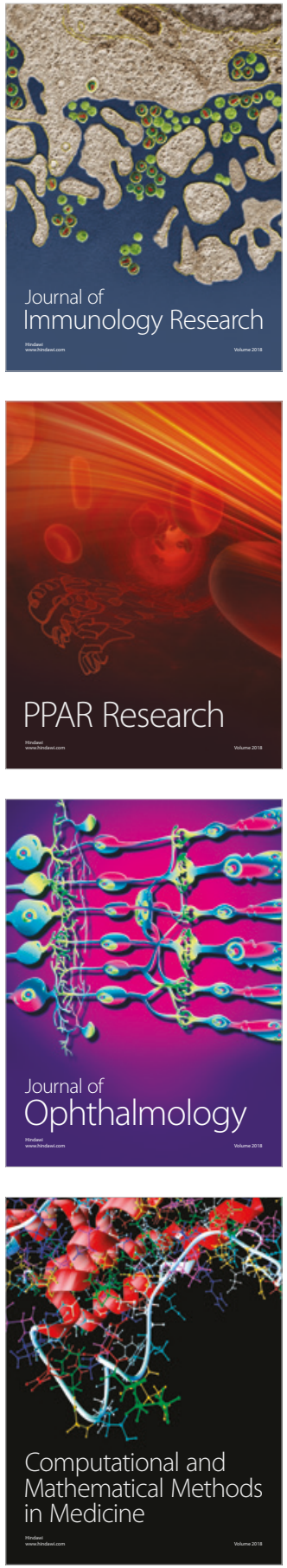

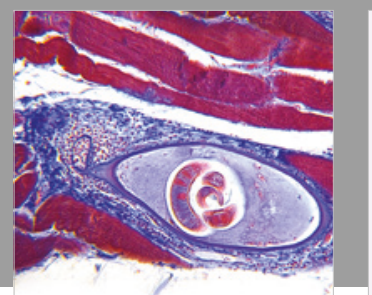

Gastroenterology Research and Practice

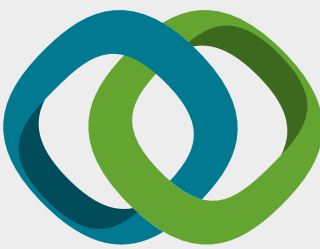

\section{Hindawi}

Submit your manuscripts at

www.hindawi.com
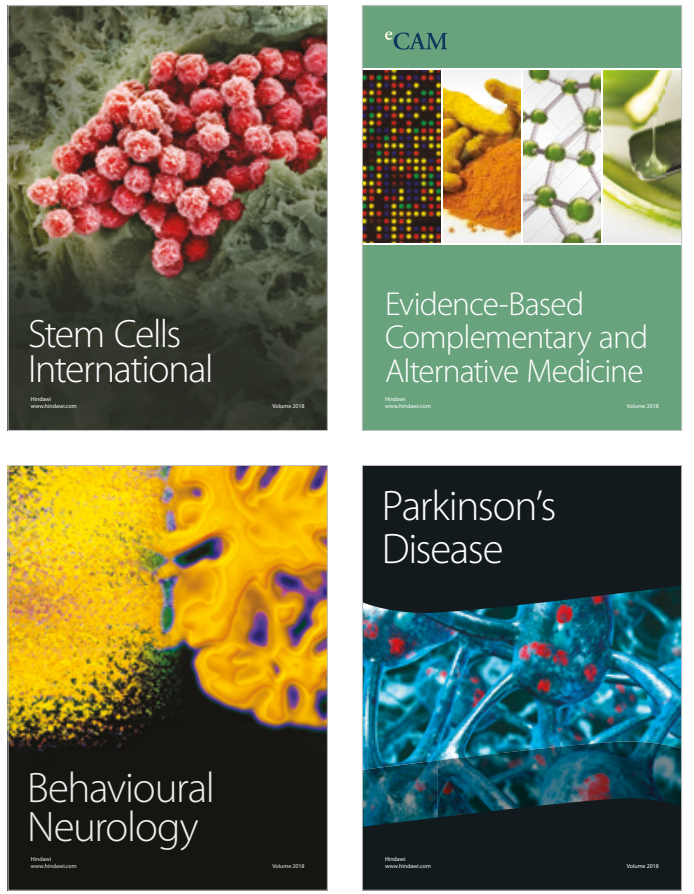

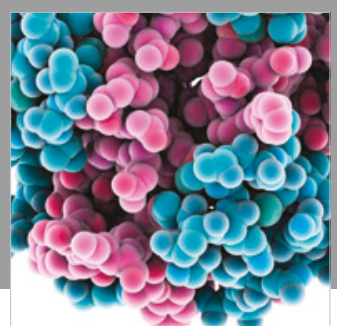

ournal of

Diabetes Research

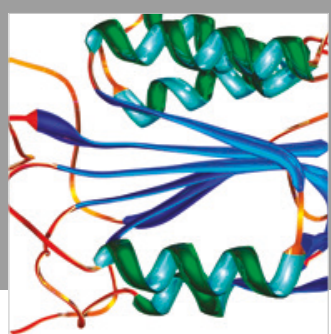

Disease Markers
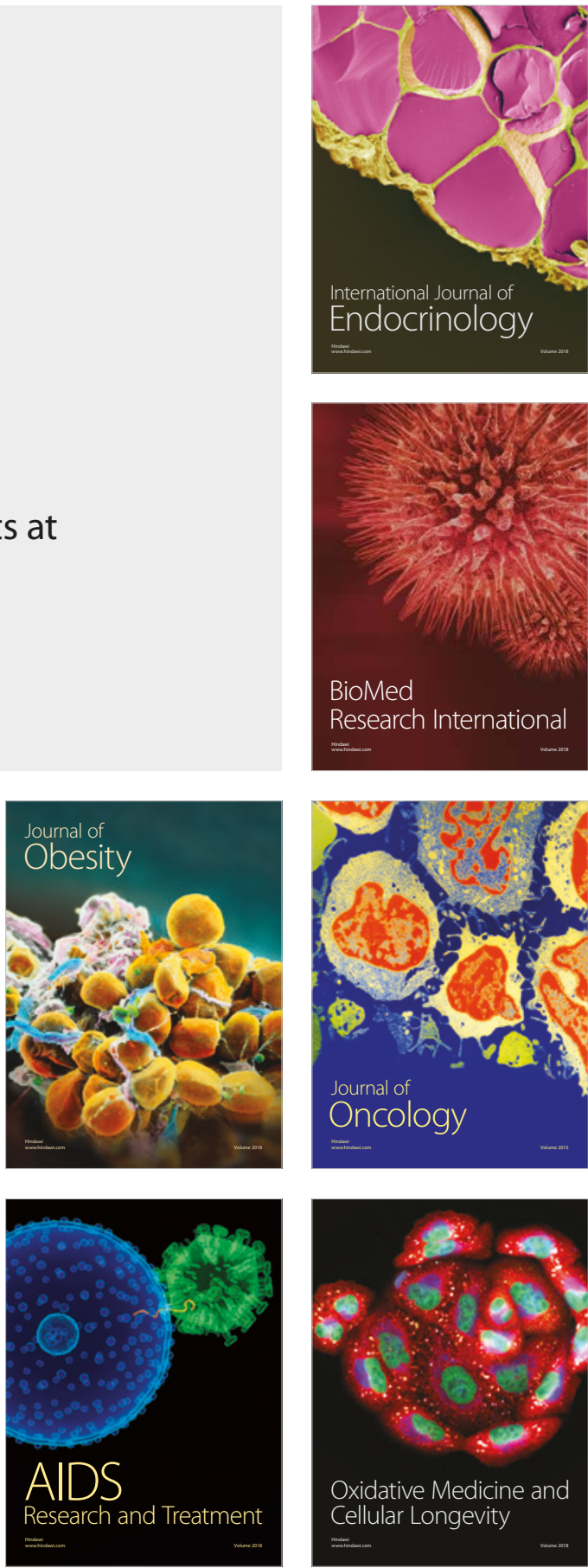